\title{
Compartilhando saberes: a experiência de acadêmicos de medicina na atenção primária à saúde
}

\author{
Sharing knowledge: the experience of medical academics in primary health care \\ Compartiendo conocimientos: la experiencia de los estudiantes de medicina en la \\ atención primária de salud
}

Maria Theresa de Alencar Ramsdorf ${ }^{1 *}$, Catherine Alexia Yoshikawa ${ }^{1}$, João Gabriel da Silva Menezes ${ }^{1}$, Luiz Fernando Benazet de Assunção Pereira'1, Osvaldo Vinícius Neto Soares'1, Tayná Boldoni Redígulo', Ana Paula Dossi de Guimarães e Queiroz'.

\section{RESUMO}

Objetivo: Relatar a experiência de acadêmicos do curso de Medicina do terceiro semestre da Universidade Federal da Grande Dourados (UFGD) em que, como parte da disciplina de Atenção à Saúde da Comunidade, foi proposto e executado um projeto de intervenção em uma Unidade Básica de Saúde (UBS) do município de Dourados - MS. Relato de experiência: Realizado a partir da vivência dos acadêmicos no acompanhamento da rotina de uma Equipe de Saúde da Família, que teve como finalidade o conhecimento do território de abrangência da UBS, o planejamento e a execução de um projeto de intervenção em resposta a uma problemática observada. Após discussões com a enfermeira responsável pela UBS, o grupo notou a necessidade da capacitação em Suporte Básico de Vida (SBV) de todos os profissionais da UBS, bem como do ensino de Primeiros Socorros Básicos em uma Escola Estadual do local. Assim, a atividade foi dividida em três etapas: capacitação dos discentes; intervenção na escola; e capacitação dos profissionais. Considerações finais: A intervenção mostrou-se satisfatória, demonstrando ser um meio de construção de conhecimento de um assunto que deveria ser administrado para todos em sociedade, além de colaborar para a compreensão dos acadêmicos de seu papel como interventor social.

Palavras-chave: Educação em saúde, Reanimação cardiopulmonar, Integração comunitária, Capacitação profissional.

\begin{abstract}
Objective: To report the experience of academics of the Medicine course of the third semester of the Federal University of Grande Dourados (UFGD) in which, as part of the discipline of Community Health Care, an intervention project was proposed and executed in a Basic Health Unit (UBS) of the city of Dourados - MS. Experience report: Carried out from the experience of academics in the follow-up of the routine of a Family Health Team, which had as its purpose the knowledge of the territory of coverage of the UBS, the planning and execution of an intervention project in response to an observed problem. After discussions with the nurse responsible for the UBS, the group noticed the necessity of training all the UBS professionals in Basic Life Support (SBV), as well as teaching Basic First Aid at a local State School. Thus, the activity was divided into three stages: training of students; intervention in the school and training of the professionals. Final considerations: The intervention proved to be satisfactory, proving to be a way of building knowledge of a subject that should be managed for all in society, in addition to collaborating for the understanding of academics of their function as social intervener.
\end{abstract}

Keywords: Health education, Cardiopulmonary resuscitation, Community integration, Professional training.

\footnotetext{
1 Universidade Federal da Grande Dourados (UFGD), Dourados - MS.

*E-mail: mariatete.99.mtar@gmail.com
} 


\section{RESUMEN}

Objetivo: Informar sobre la experiencia de los estudiantes del curso de Medicina del tercer semestre de la Universidad Federal de Grande Dourados (UFGD) en el que, como parte de la disciplina de Salud Comunitaria, se propuso y ejecutó un proyecto de intervención en una Unidad Básica de Salud (UBS) de la ciudad de Dourados - MS. Informe de experiencia: Realizado a partir de la experiencia de los estudiantes en el acompañamiento de la rutina de un Equipo de Salud de la Familia, que tenía como finalidad el conocimiento del territorio de cobertura de la UBS, planificación y ejecución de un proyecto de intervención en respuesta a un problema observado. Después de discutir con la enfermera responsable de la UBS, el grupo señaló la necesidad de entrenamiento en Soporte Vital Básico (SBV) de todos los profesionales que trabajan en la UBS, así como la enseñanza de Primeros Auxilios en una Escuela Estatal local. En este contexto, la actividad se dividió en tres etapas: a) formación de los estudiantes; b) intervención en la escuela; c) formación de los profesionales de la UBS. Consideraciones finales: La intervención resultó ser satisfactoria, demostrando ser un medio de construir el conocimiento de un tema que debería ser manejado por todos en la sociedad, además de colaborar para la comprensión de los estudiantes de su papel como interventores sociales.

Palabras clave: Educación en salud, Reanimacíon cardiopulmonar, Integración a la comunidad, Capacitación profesional.

\section{INTRODUÇÃO}

Não é raro atentar-se aos noticiários cotidianos e perceber a grande quantidade de notícias relacionadas a acidentes como queimaduras, envenenamentos e principalmente a parada cardiorrespiratória (PCR). Conhecer bem o Suporte Básico de Vida (SBV) para situações como essas é algo essencial na vida da população brasileira, pois o atraso no reconhecimento e tratamento dos sintomas é responsável por cerca de 80\% dos óbitos no ambiente extra-hospitalar (MESQUITA ET, 1999 apud PERGOLA AM e ARAUJO EM, 2009). Dentro desse contexto, salienta-se a gravidade da PCR, que é descrita como a interrupção das atividades respiratórias e circulatórias estáveis e pode levar um indivíduo a óbito em minutos. Dessa forma, a intervenção para reverter o quadro tem como princípios fundamentais a aplicação de um conjunto de procedimentos para reestabelecer a circulação e a oxigenação interrompidas (SANTOS LP, et al., 2013).

Paralelamente, conforme a Política Nacional de Atenção Básica (PNAB), aprovada pela Portaria № 2436/2017 (MINISTÉRIO DA SAÚDE, 2017), a Atenção Básica é a porta de entrada preferencial das Redes de Atenção à Saúde (RAS) e o primeiro atendimento de casos de urgência/emergência, sendo responsável pelo acolhimento e pela organização de ações e estratégias conforme as necessidades e demandas da sua população adscrita. Dessa forma, as Unidades Básicas de Saúde (UBS) se configuram como elementos essenciais para um cuidado continuado e integral, além de serem o ponto de partida das ações de prevenção e promoção da saúde.

Tendo em vista sua importância, é imperativa a existência de uma base para orientar a atuação das UBS, tal qual no Art. 4.1 da PNAB, em que estão descritas as Atribuições Comuns aos membros das Equipes que atuam na Atenção Básica, entre elas a de instituir ações e medidas para a segurança do paciente e promoção da saúde. Além disso, conforme expresso no Art. 4.2.5, cabe ao Gerente de Atenção Básica utilizar os recursos físicos e tecnológicos da UBS em todo seu potencial partindo da orientação à equipe acerca do uso adequado de tais recursos. Outrossim, o processo de trabalho das equipes deve se organizar para permitir que casos de urgência/emergência tenham prioridade no atendimento, independentemente do número de consultas agendadas no período, provendo atendimento e suporte adequados até que os usuários sejam acolhidos por outros pontos de atenção da RAS.

Além disso, é valido ressaltar que outros projetos similares já existem, como o Kids Save Lives, que é apoiado pela Organização Mundial de Saúde (OMS) desde 2015 (KIDS SAVE LIVES, 2015). Tal projeto, representado no Brasil pela Faculdade de Medicina da Universidade de São Paulo (FMUSP) e agregado 
como disciplina optativa aos graduandos, ensina docentes e discentes do Ensino Fundamental II e Ensino Médio de escolas públicas a identificar sinais de PCR e acidente vascular cerebral (AVC), e quais os procedimentos em tais situações, a exemplo da reanimação cardiopulmonar (ASSESSORIA DE COMUNICAÇÃO DA FMUSP, 2018).

Diante do exposto, os acadêmicos do terceiro semestre do curso de medicina da Universidade Federal da Grande Dourados (UFGD), como parte da disciplina de Atenção à Saúde da Comunidade, elaboraram um projeto de capacitação em SBV dos profissionais de uma UBS e de ensino de Primeiros Socorros para alunos de uma escola estadual do município de Dourados - MS. Tal proposta tornou-se possível apenas ao adquirir o conhecimento supracitado sobre a Atenção Básica em si, sua constituição e importância dentro da sociedade. Portanto, este trabalho tem como objetivo relatar a experiência dos acadêmicos no intercâmbio de aprendizados que se deu com a população em conjunto com a equipe da UBS, bem como relatar a execução e os resultados das intervenções realizadas na unidade e na escola estadual.

\section{RELATO DE EXPERIÊNCIA}

O relato de experiência é baseado na vivência dos acadêmicos do terceiro semestre do curso de medicina da UFGD em uma UBS do município de Dourados/MS e referente à disciplina de Atenção à Saúde da Comunidade. A dinâmica de visitas semanais propiciadas por essa disciplina tem como objetivo ajudar os estudantes a compreender a organização da Atenção Básica na prática, acompanhando Agentes Comunitários de Saúde (ACS) durante visitas domiciliares e conhecendo o funcionamento da UBS. Além disso, possibilita que os discentes proponham e executem uma intervenção cabível em resposta a uma problemática observada.

Ao longo das visitas, os acadêmicos puderam observar o perfil epidemiológico da população adscrita, destacando-se como doenças prevalentes a hipertensão arterial sistêmica, diabetes mellitus, infecções sexualmente transmissíveis (IST's), obesidade, câncer e doenças psiquiátricas, além de alguns casos de alcoolismo e gravidez na adolescência. Também foi possível identificar adversidades no funcionamento da UBS, a saber:

Inaplicação da contrarreferência, o que dificulta o acompanhamento e tratamento dos pacientes e inviabiliza a comunicação com a Atenção Secundária;Ausência de capacitação dos profissionais em SBV, tornando a UBS inapta para lidar com urgências/emergências; Necessidade de uma terceira Equipe de Saúde da Família (eSF) para auxiliar as duas já existentes a cobrir toda a região, devido ao crescimento acentuado da população nos últimos anos;Curto período de permanência dos médicos pelo fato da UBS ser distante do centro da cidade, o que é um empecilho para o atendimento integral dos pacientes.

Após a análise dos acadêmicos, decidiu-se que a capacitação em Primeiros Socorros era a principal adversidade a ser remediada por um projeto de intervenção. A equipe apoiou a proposta, pois a Unidade possuía o Desfibrilador Externo Automático (DEA) e o dispositivo bolsa-válvula-máscara desde 2017, mas seus profissionais nunca haviam recebido a capacitação para utilizá-los.

Concomitantemente, foi proposta a capacitação em Primeiros Socorros Básicos de estudantes e professores


região, visto que crianças e adolescentes podem se envolver em acidentes e necessitar de cuidados até o atendimento especializado chegar. Portanto, o objetivo foi ensinar como proceder em situações de queimaduras, desmaios, convulsões, paradas cardiorrespiratórias (PCR), entre outros.Dessa maneira, a intervenção foi dividida em três etapas: a) aulas capacitatórias do grupo de acadêmicos; b) aplicação da intervenção na escola; c) capacitação dos profissionais da UBS.

\section{Capacitação dos discentes}

Os seis integrantes do grupo foram à sede do Serviço de Atendimento Móvel de Urgência (SAMU) da região para assistir a uma aula expositiva e prática a respeito de emergências clínicas, identificação de PCR, RCP de alta qualidade, suporte básico no trauma, cuidado de hemorragias e fraturas e também estabilização, elevação e transporte de vítimas. 
Também foi realizada uma capacitação conduzida por uma enfermeira certificada pela American Heart Association (AHA) e com uso de bonecos adulto e pediátrico para treino de RCP, emprestados pelo Laboratório de Habilidades Médicas da Faculdade de Ciências da Saúde (FCS) da UFGD. Foram abordadas a identificação dos sinais da PCR e a aplicação de RCP de alta qualidade, além do manejo adequado do DEA, manobras de Heimlich e de reanimação de lactentes.

\section{Intervenção na escola}

O grupo realizou a capacitação de Primeiros Socorros Básicos de estudantes e professores da escola estadual por meio de uma aula teórica mesclada com perguntas e relatos de caso, a fim de buscar maior interação com os adolescentes. Ao final de cada palestra, os estudantes foram ouvidos e, de forma coletiva, pediu-se que opinassem sobre a apresentação, classificando-a como ótima, boa, regular ou ruim.

\section{Capacitação dos profissionais da UBS}

O grupo contou com a ajuda de emergencistas do SAMU e buscou ensinar todos os profissionais da Unidade, uma vez que todos devem ter conhecimento e confiança para atuar em situações de PCR ou de engasgo.

Ao final, durante uma conversa com os participantes, esses foram convidados a opinar sobre o projeto apresentado quanto à qualidade da apresentação e quanto à assimilação da atividade. Por fim, como forma de auxiliá-los a relembrar os procedimentos, foi fixado no local um cartaz revisando a utilização correta do DEA e os principais dados para realização da RCP (Quadro 1).

Em relação aos resultados, no que concerne a capacitação de Primeiros Socorros Básicos realizada na escola, dos 123 alunos que participaram, 80 classificaram a apresentação como ótima, 37 como boa, 5 como regular e 1 como ruim. Os estudantes interagiram, esclareceram dúvidas e responderam a questionamentos dos discentes, demonstrando assim ter assimilado os aspectos mais importantes da capacitação, como o acionamento do SAMU em situações de PCR, os cuidados à vítima de convulsão e como proceder em situações de engasgo. Dessa forma, o resultado foi considerado satisfatório.

Outrossim, quanto à capacitação da equipe da UBS, 16 pessoas classificaram-na como boa e 2 como razoável, mas todos afirmaram assimilar as técnicas. Com o auxílio de emergencistas do SAMU, a capacitação foi conduzida com o ensino da parte prática complementada oralmente por informações teóricas. Vale ressaltar o fato de que ao manusear o DEA da UBS, descobriu-se a ausência, por motivo desconhecido, do atenuador para carga pediátrica, uma peça essencial que reduz os joules liberados no choque em crianças menores de oito anos de idade.

Quadro 1 - Cartaz para revisão acerca do manejo do DEA.

\begin{tabular}{|c|l|}
\hline Passo & \multicolumn{1}{c|}{ Ação } \\
\hline 1 & $\begin{array}{l}\text { Abra o estojo de transporte. Ligue o DEA, se necessário. } \\
\text { - Alguns dispositivos são ligados automaticamente quando você abre a tampa ou o estojo. } \\
\text { - Ligue os cabos de conexão das pás ao DEA. } \\
\text { - Siga as instruções do DEA para se orientar sobre os passos subsequentes. }\end{array}$ \\
\hline 2 & $\begin{array}{l}\text { Remova o papel adesivo protetor das pás do DEA e aplique-as no tórax desnudo da vítima. } \\
\text { Escolha pás para adulto para vítimas de } 8 \text { anos de idade ou acima. } \\
\text { - Siga as ilustrações de posicionamento das pás. } \\
\text { - Para vítimas menores de } 8 \text { anos de idade, usar as pás pediátricas e instalar a chave para modo } \\
\text { pediátrico. }\end{array}$ \\
\hline 3 & $\begin{array}{l}\text { Quando o DEA instruir, afaste-se da vítima e permita que ele analise o ritmo. } \\
\text { - Quando o DEA estiver analisando o ritmo, certifique-se de que ninguém esteja tocando na vítima. } \\
\text { - O DEA pode levar alguns segundos para analisar. } \\
\text { - Ele o instruirá se um choque for necessário. }\end{array}$ \\
\hline
\end{tabular}

Fonte: Ramsdorf MTA, et al., 2020. 


\section{DISCUSSÃO}

Foi realizada pelo grupo de acadêmicos a capacitação em Primeiros Socorros dos funcionários de uma das UBS do município por um projeto de intervenção. A equipe apoiou a proposta, pois a Unidade possui o DEA e o dispositivo bolsa-válvula-máscara desde 2017, mas seus profissionais nunca receberam a capacitação acerca da correta forma de utilizá-los, mesmo sendo reconhecida a necessidade do aprendizado e atualização acerca do SBV (SANTOS TCMM, et al., 2011; FERREIRA JAB, et al., 2012).

Ademais, fez-se a capacitação em Primeiros Socorros Básicos de estudantes e professores do 8ำ e 9o anos do Ensino Fundamental II e do $1^{\circ}, 2^{\circ}$ e $3^{\circ}$ anos do Ensino Médio da escola estadual da região, com o objetivo de ensinar e reforçar procedimentos em situações de queimaduras, desmaios, convulsões, PCR e outros. A ação esteve em congruência com a Lei no 13.722, sancionada em 2018 pelo então Presidente Michel Temer. Esta torna obrigatória a capacitação em noções básicas de Primeiros Socorros de professores e funcionários de estabelecimentos de ensino públicos e privados de educação básica (BRASIL, 2018).

Nesse contexto, a importância do ensino de SBV nas escolas consiste em reduzir o número de mortes por Primeiros Socorros não prestados, visto que muitos não têm conhecimento e presumem que cometerão erros (BANFAl B, et al., 2017). Assim, a disseminação da prática correta entre os alunos atinge um público maior, pois esses discutem o aprendizado com familiares, conscientizando e influenciando a busca por cursos tradicionais de treinamento (CONNOLLY M, et al., 2007).

Não obstante, sendo a Atenção Primária a porta de entrada do sistema de saúde, espera-se que casos de urgência/emergência possam vir a ocorrer em uma UBS. Dessa forma, os profissionais presentes devem estar aptos a lidar com tais situações até que se obtenha ajuda especializada. Assim, treinamentos e aulas devem ser conduzidos periodicamente para as equipes, visando fixar conteúdos e práticas, pois mesmo entre profissionais treinados pode não haver homogeneidade de conhecimentos e técnicas (MARTíNEZ JAC, et al., 2018).

Nesse sentido, em relação à UBS, nota-se que o interesse não foi uniforme entre os profissionais. Mesmo que alguns demonstrassem preocupação em aprender e assimilar o conteúdo passado e de participar das práticas de RCP, outros sequer se interessaram em praticar a manobra. Desencorajador também foi o fato de ninguém se dispor a praticar a manobra de Heimlich no boneco pediátrico, algo preocupante, visto que, segundo a ONG Criança Segura, em 2017, foram registrados 581 óbitos por engasgamento de crianças menores de um ano de idade (CRIANÇA SEGURA, 2017).

Acerca desse assunto, para verificar se há ou não melhoria no desempenho de cidadãos treinados em SBV, um estudo prospectivo foi realizado com trinta e quatro profissionais de saúde do Reino Unido. Como resultado, constatou-se que ao final do treinamento houve melhorias significativas na proporção daqueles que realizaram uma abordagem segura, uma correta abertura das vias aéreas, um fornecimento de compressão correta em relação à ventilação, dentre outros (MELLOR R, WOOLLARD M, 2009).

Outro ponto a ser ressaltado é o fato de a UBS possuir o DEA e o dispositivo bolsa-válvula-máscara há dois anos, mas nunca ter sido capacitada para utilizar tais equipamentos. De acordo com o que foi relatado, casos de PCR não são comuns na região, o que pode explicar porque o assunto nunca foi tratado com urgência. Entretanto, independentemente da incidência, funcionários da UBS devem saber proceder no atendimento em situações de urgência/emergência até a chegada do suporte especializado, conforme preconizado no Art. 5ํ da PNAB (MINISTÉRIO DA SAÚDE, 2017).

Dessa forma, considerando que a ação efetiva e imediata e o fornecimento do SBV de alta qualidade diante de uma parada cardíaca são alguns dos fatores cruciais para evitar danos neurológicos, espera-se que o conhecimento e a capacidade de prestar tal suporte sejam amplos, tanto entre a população leiga quanto entre os profissionais da saúde. No entanto, um estudo realizado em Israel concluiu que muitas clínicas de cuidado primário estão subequipadas e que grande parte dos médicos que as atendem está mal preparada para fornecer os serviços essenciais para salvar vidas (EINAV S, et al., 2017). 
Outrossim, a importância dos funcionários da UBS saberem manusear o DEA baseia-se no fato de que metade dos casos de PCR no Brasil ocorre no ambiente pré-hospitalar (ZANDOMENIGHI RC, et al., 2018). Destes, quase $80 \%$ dos casos se relacionam com dois acometimentos: Fibrilação Ventricular e Taquicardia Ventricular, ritmos com bom prognóstico de reversão se tratados com rapidez e perspicácia (BERNOCHE C, et al., 2019). Por isso, o conhecimento sobre a utilização do DEA é de extrema importância, pois ele proporciona o atendimento necessário, já que esses são os dois ritmos que o dispositivo é capaz de desfibrilar (RINGH M, et al., 2018).

Não só isso, conforme observado após as visitas domiciliares junto às ACS, o diabetes mellitus e a hipertensão arterial sistêmica são as doenças prevalentes na região e ambas são fatores de risco para PCR, como mostram estudos (AUNE D, et al., 2018; RAPSOMANIKI E, et al., 2018). Considerando, ainda, a distância da região até a Unidade de Pronto Atendimento (UPA) do município de Dourados ou a sede do SAMU, a UBS seria o primeiro ponto de atenção que a população recorreria, e os cuidados prestados ali seriam determinantes para a sobrevivência e bom prognóstico da vítima (MORAIS DA, et al., 2014).

Mas, apesar dessas considerações, deve-se destacar que, embora o contingente de profissionais preocupados com a capacitação não tenha atingido o esperado, houve pessoas que se atentaram e participaram do projeto adequadamente, portanto, caso ocorra uma situação de PCR ou sufocamento, as vítimas não estarão desamparadas.

Por fim, a capacitação dos graduandos em SBV pela enfermeira supracitada deve ser ressaltada, pois, além de ter sido uma experiência única de aprendizado, proporcionou conhecimento e técnica imprescindíveis no cuidado à vítima de PCR ou sufocamento. Ademais, tal atividade, em conjunto às intervenções executadas, inspirou a criação do projeto de extensão que visa à capacitação em SBV para profissionais de outras UBS, alunos de escolas estaduais e municipais de Dourados, e gestantes adscritas ao Hospital Universitário da Universidade Federal da Grande Dourados (HU-UFGD).

\section{REFERÊNCIAS}

1. AUNE D, et al. Diabetes mellitus and the risk of sudden cardiac death: A systematic review and meta-analysis of prospective studies. Nutrition, Metabolism, \& Cardiovascular Diseases. 2018; 28(6): 543-556.

2. BANFAI B, et al. 'The year of first aid': effectiveness of a 3-day first aid programme for 7-14-year-old primary school children. Emerg Med J. 2017; 34(8):526-532.

3. BERNOCHE C, et al. Atualização da Diretriz de Ressuscitação Cardiopulmonar e Cuidados de Emergência da Sociedade Brasileira de Cardiologia - 2019. Arq Bras Cardiol. 2019; 113(3): 449-663.

4. BRASIL. LEI № 13.722, DE 4 DE OUTUBRO DE 2018. Torna obrigatória a capacitação em noções básicas de primeiros socorros de professores e funcionários de estabelecimentos de ensino públicos e privados de educação básica e de estabelecimentos de recreação infantil. Diário Oficial [da] República Federativa do Brasil, Brasília, DF, 4 out. 2018.

5. BRASIL. Ministério da Saúde. PORTARIA № 2.436, DE 21 DE SETEMBRO DE 2017. Aprova a Política Nacional de Atenção Básica, estabelecendo a revisão de diretrizes para a organização da Atenção Básica, no âmbito do Sistema Único de Saúde (SUS). Diário Oficial [da] República Federativa do Brasil, Brasília, DF, 21 set. 2017.

6. CONNOLLY M, et al. The 'ABC for life' programme - teaching basic life support in schools. Resuscitation. 2007 Feb; 72(2): 270-9.

7. CRIANÇA SEGURA. Conheça os dados sobre acidentes. Disponível em: https:// criancasegura.org.br/dados-deacidentes/. Acesso em: 30 out. 2019.

8. EINAV S, et al. Cardiopulmonary arrest in primary care clinics: more holes than cheese: a survey of the knowledge and attitudes of primary care physicians regarding resuscitation. Isr J Health Policy Res. 2017; 10; 6:22.

9. FERREIRA JAB, et al. Perfil e conhecimento teórico de médicos e enfermeiros em parada cardiorrespiratória, município de Rio Branco, AC. Revista brasileira de cardiologia; 2012; 25(6): 464-470.

10. ASSESSORIA DE COMUNICAÇÃO DA FMUSP. Projeto de extensão Kids Save Lives ganha as salas de aula como disciplina do primeiro semestre de 2019. Disponível em: http://www.fm.usp.br/fmusp/noticias/projeto-de-extensaokids-save-lives-ganha-as-salas-de-aula-como-disciplina-do-primeiro-semestre-de-2019. Acesso em: 31 out. 2019.

11. KIDS SAVE LIVES. 'Kids Save Lives' statement has been endorsed by the World Health Organisation. Disponível em: https://www.kids-save-lives.eu/statement.html. Acesso em: 31 out. 2019. 
12. MARTÍNEZ JAC, et al. Self-Perception of Theoretical Knowledge and Practical Skills by Primary Health Care Physicians in Life-Threatening Emergencies. Prehosp Disaster Med. 2018; 33(5):508-518.

13. MELLOR R, WOOLLARD M. Skill acquisition by health care workers in the Resuscitation Council (UK) 2005 Guidelines for Adult Basic Life Support. Int Emerg Nurs. 2010; 18(2):61-6.

14. MORAIS DA, et al. Parada cardíaca extra-hospitalar: fatores determinantes da sobrevida imediata após manobras de ressuscitação cardiopulmonar. Revista Latino-Americana de Enfermagem. 2014; 22(4): 562-8.

15. PERGOLA AM, ARAUJO EM. O leigo e o suporte básico de vida. Rev. esc. enferm. USP, São Paulo, 2009; 43(2): 335-342.

16. RAPSOMANIKI E, et al. Blood pressure and incidence of twelve cardiovascular diseases: lifetime risks, healthy lifeyears lost, and age-specific associations in 1.25 million people. Lancet. 2014; 383(9932): 1899-1911.

17. RINGH M, et al. The challenges and possibilities of public access defibrillation. J Intern Med. 2018; 283(3): 238-256.

18. SANTOS LP, et al. Parada cardiorrespiratória: principais desafios vivenciados pela enfermagem no serviço de urgência e emergência. Revista Interdisciplinar em Saúde, Cajazeiras, 2016; 3(1): 35-53.

19. SANTOS TCMM, et al. Conteúdo de domínio da equipe de enfermagem de um pronto socorro sobre o atendimento à parada cardiorrespiratória. Revista de enfermagem UFPE on line. 2011; 5(10): 2445-2455.

20. ZANDOMENIGHI RC, MARTINS EAP. Análise Epidemiológica dos Atendimentos de Parada Cardiorrespiratória. Rev enferm UFPE online. Recife, 2018; 12(7):1912-22. 